\title{
Evaluation of Serum Zinc Levels in Hyperbilirubinemic Neonates Before and After Phototherapy
}

\author{
Nashwa M Samra ${ }^{1}$, AhmedAbd El Moktader ${ }^{2}$,Howaida A Abdel Rasoul ${ }^{3}$, Dr.Rania M \\ Lotayef $^{4}$
}

1. Professor and head of Internal Medicinedepartment,Faculty of Medicine, Fayoum University.

2. Prof.of clinical pathology,Faculty of medicine, FayoumUniversity.

3. Lecturer of Internal Medicine,Faculty of Medicine, Fayoum University.

4. M.B.B.CH, Fayoumuniversity, Egypt.

\section{Abstract:}

- Background: Neonatal hyperbilirubinemia is a common clinical problem encountered during neonatal period. Zinc can reduce phototherapy duration by precipitating unconjugated bilirubin in the intestine however, zinc toxicity is an issue that must be considered since theoretically bilirubin reduction by phototherapy may increase serum zinc levels

- Purpose: To study the effect of phototherapy on serum zinc level of hyperbilirubenimicfull term newborn.

- Patients and Methods: This prospective cohort study was conducted in Fayoum University Hospital in the period from December 2017 to February 2018 after obtaining ethical approvals and informed consents. This study recruited 50 full term neonates admitted to the noenatoal intensive care units (NICU) ofFayoum University Hospital with indirect hyperbilirubinemia and requiring phototherapy according to the American Academy of Pediatrics guidelines 2004.

- Results: There was a highly statistically significant increase in the level of zinc after phototherapy than before phototherapy with $\mathrm{p}$ value $<0.001$.

- Conclusion: Serum zinc was increased significantly after phototherapy which potentially may cause zinc toxicity.

- Keywords: Hyperbilirubinemia, Zinc, Phototherapy, Neonatal Jaundice. 


\section{Evaluation of Serum Zinc Levels in Hyperbilirubinemic Neonates Before and After Phototherapy}

\section{Introduction:}

Deposition of indirect bilirubin in the neuron membrane leads to permanent neuronal injury. Prevention of bilirubin encephalopathy and its chronic sequels is the essential aim of detecting and treating neonatal hyperbilirubinemia (1). Therapeutic options for unconjugated hyperbilirubinemia in neonates, like phototherapy and blood exchange transfusion are costly, timeconsuming and potentially risky ${ }^{(2)}$. New therapeutic methods appear to be necessary to decrease elevated serum bilirubin. One of the possible therapies for preventing bilirubin neurotoxicity is via reducing the unconjugated bilirubin level by inhibition of enterohepatic circulation $^{(3)}$. Zinc salts have a potential to inhibit enterohepatic circulation of bilirubin probably by precipitating unconjugated bilirubin in the intestine ${ }^{(4)}$. Accordingly, some clinical trials have evaluated the effects of zinc supplementation on hyperbilirubinemic neonates undergoing phototherapy ${ }^{(5)}$. The chemical structure of bilirubin has the potential to chelate metal ions, such as zinc.
As a result, bilirubin reduction by phototherapy may cause an increase in serum zinc levels. In this situation, additional zinc supplementation may bring about zinc toxicity (6). (Blindauer, 2013).

\section{PATIENTS AND METHODS}

This prospective cohort study was conducted in Fayoum University Hospital in the period from September 2018 to February 2019. This study recruited 50 full term neonates admitted to the neonatal intensive care units (NICU) of Fayoum University Hospital with indirect hyperbilirubinemia and requiring phototherapy according to the American Academy of Pediatrics guidelines 2004.

divided into 2 groups:

- Group(1):Neonates with serum bilirubin $<18 \mathrm{mg} / \mathrm{dl}$ (18 neonates) .

- Group (2): Neonates with serum bilirubin $\geq 18 \mathrm{mg} / \mathrm{dl}$ (32 neonates) .

- Inclusion Criteria: Full-term newborns (GA $<37$ weeks), birth weight $>2500$ gm and with clinically evident jaundice with an onset between 2-7 days.

- Exclusion Criteria: Newborn undergoing exchange transfusion, apparent congenital anomalies and sepsis.

All patients and controls included in the study were subjected to the following:

1- Detailed maternal, obstetric and neonatal history:.

2- Clinical data: Weight, length. Gestational age. Vital signs. Neonatal reflexes. Examination to assess zinc toxicity.

\section{Investigations:}


1. Determination of serum bilirubin: Serial serum bilirubin measurements were repeated on daily bases. Total serum bilirubin direct and indirect bilirubin was measured.

2. Blood group and RH determination: Hemoglobin, hematocrit levels and reticulocytic count were also done.

3. To exclude sepsis: Determination of CRP, $\mathrm{CBC}$

\section{Serum Zn assay:}

Total serum zinc levels were measured beforeand 12 - 24 hours after termination of phototherapy .The determination of serum zinc levels were carried out by atomic absorption spectrometry method using AAnalyst 800(Perkin Elmer USA). Serum zinc level according to the instrument: 50 - 150 $\mathrm{mcg} / \mathrm{ml}$. Toxic level $>200 \mathrm{mcg} / \mathrm{ml}$

\section{. Statistical analysis}

The collected data was organized, tabulated and statistically analyzed using SPSS software statistical computer package version 22 (SPSS Inc, USA). For quantitative data, the mean and standard deviation were calculated. Comparison between any two groups as regards study variableswas done using Independent t-test. Qualitative data was described as frequencies (number) and percentages; chi- square test was used as a test of significance. For interpretation of results of tests of significance,significance was adopted at $\mathrm{P} \leq 0.05$.

\section{. Ethical considerations:}

The study was reviewed by the faculty of medicine research Ethical Committee. The researcher informed the participants about the objectives of the study, the examination and investigations that were done. Also the confidentiality of their information and their right not to participate in the study were considered.

\section{$\underline{\text { Results: }}$}

Our study included 50 cases and were divided into group(1) With TSB $<18 \mathrm{mg} / \mathrm{dL}$ and group (2) with TSB $\geq 18 \mathrm{mg} / \mathrm{dL}$. The mean age of presentation was approximately 76.8 hours, while the majority of patients were males and delivered with cesarean section method in both groups. The age at presentation was not statistically significantly in patients of both groups $(81.78 \pm 14.22$ vs. $73.88 \pm 16.69, \mathrm{p}<0.0078)$. There was no statistical significance correlation between serum zinc before phototherapy and the studied parameters, there was no statistically significant correlation between serum zinc level and mode of delivery and the gender of the neonates either before or after phototherapy. There was no statistical significant difference between patients less and more than $18 \mathrm{mg} / \mathrm{dl}$ regarding hematological profile.. In table (1) we divided the studied group $(n=50)$ into two groups according to TSB level. As group 1 was for infants with TSB $<18(\mathrm{n}=18)$ and group 2 for infants with TSB TSB $\geq 18(\mathrm{n}=32)$. The table shows that the mean of total serum bilirubin before phototherapy for group 1 was $16.94 \pm$ 0.55 while in group 2 was $19.61 \pm 1.11$. After phototherapy the level of TSB was $9.27 \pm 0.64$ in group 1 and $9.13 \pm 0.94$ in group 2 .The total serum bilirubin was significantly higher 
in group 2 before phototherapy ( $p<0.001)$ but no difference after phototherapy. Table (2)shows that newborns among group 2 received shorter duration of phototherapy (54 \pm $11.06 \mathrm{hrs})$ compared to group $1(63.36 \pm 11.12$ hrs) and this difference was a highly statistically significant $(\mathrm{p}<0.001)$. Phototherapy was associated with highly statistically significant increase in the serum zinc level in neonates with severe hyperbilirubinemia (TSB $>18 \mathrm{mg} / \mathrm{dL}$ ). Our study showed that the serum zinc level statistically significantly increased after phototherapy to reach $129.17 \mathrm{mcg} / \mathrm{mL}$ (p $<0.001$ ) in patients with mild-to-moderate hyperbilirubinemia and $187.37 \mathrm{mcg} / \mathrm{mL}$ (p $<0.001)$ in patients with severe hyperbilirubinemia (table3) .

\section{Discussion:}

As regard to the type and duration of phototherapy, there was a statistically significant higher proportion of patients who underwent intensive phototherapy in the group(2) with severe hyperbilirubinemia compared to the other study group (1) $(94 \%$ versus $0 ; \mathrm{p}<0.001)$. The current evidence in agreement with study done by Hansen et al., $\mathbf{2 0 1 5}^{(\mathbf{7})}$ which indicates that aggressive implementation of phototherapy results in a clinically significant rate of bilirubin decrease, and that neonates with severe hyperbilirubinemia needs more excessive phototherapy to reduce the need for exchange transfusion and possibly reduce the severity of bilirubin neurotoxicity.

In our study, there was a statistically significant increase in the level of zinc after phototherapy than before phototherapy with $\mathrm{p}$ value $<0.001$. That is in agreement with the study done by Ahmadpour-kachoet al. $\mathbf{( 2 0 1 7 )}^{(\mathbf{8})}$ on 105 studied neonates therewas a statistically significant increase in the level of zinc after phototherapy than before with pvalue < 0.001.Also in agreement with Boskabadi et al. (2015) ${ }^{(\mathbf{9})}$ on a study done on 263 neonates found that there was a statistically significant increase in the level of zinc $(\mu \mathrm{g} / \mathrm{dl})$ after phototherapy than before phototherapy with p-value $<0.001$. Our study showed that the serum zinc level increased significantly after phototherapy in both study groups ( $p$ <0.001). Moreover, the average serum zinc level was significantly higher in patients group (2)with sever hyperbillirubinemia compared to other study group ( (group 1) 129.17 versus (group 2) $187.37 \mathrm{mg} / \mathrm{mL}$, respectively; $\mathrm{p}<0.001)$.

Saravanan and colleagues.,2017 ${ }^{(10)}$ performed a prospective cohort study to estimate serum zinc level alterations before and after phototherapy, in jaundiced newborns. Their results showed that phototherapy was associated with a significant increase in the serum zinc level in neonates with (TSB >18 mg/dL) but not in those with (TSB<18 mg/dL).). Our results showed that higher proportion of patients with severe hyperbilirubinemia suffered fromzinc levels > $200 \mathrm{mg} / \mathrm{dL}$ after phototherapy compared to patients with TSB $<18 \mathrm{mg} / \mathrm{dL}$, however, the results was borderline statistically significant ( $8 \%$ versus $0 ; p=0.059)$. Also, Saravanan 
and colleagues.,2017 ${ }^{(\mathbf{1 0})}$ reported that phototherapy caused a significant increase in the level of zinc with potentially toxic levels in neonates with (TSB more than $18 \mathrm{mg} / \mathrm{dl}$ ). Similarly, Mosayebi and colleagues.,2016 ${ }^{(11)}$ showed that there was a significant increase in the percentage of neonates with zinc levels > $200 \mathrm{mg} / \mathrm{dL}$ after phototherapy in neonates in group 2 with sever hyperbillirubinemia..El-Mazary and colleagues, $2017^{(\mathbf{1 2})}$ assessed the changes in serum levels of a number of trace elements (copper, zinc, and magnesium) after intensive phototherapy in full term neonates with indirect hyperbilirubinemia. The results had no effect on serum zinc level and did not change it significantly.

\section{Conclusion:}

Phototherapy causes significant increase in serum zinc level, regardless of the severity of hyperbilirubinemia.

However, it may induce zinc toxicity. Future research should be directed towards evaluating the safety of zinc salts for lowering bilirubin levels in neonates with hyperbilirubinemia.

\section{RECOMMENDATIONS}

1. Further researches on the efficacy of zinc salts in inhibition of enterohepatic circulation for treatment of hyperbilirubinemia, but with using insoluble zinc salts to avoid zinc toxicity.

2. More studies in evaluation of the role of phototherapy in rising serum zinc in hyperbilirubinemia.

\section{References:}

Hyperbilirubinemia and kernicterus. ClinPerinatol. (33): 387-410.

(2) Wong R.J and BhutaniVK (2013): Treatment of unconjugated hyperbilirubinemia in term and late preterm Journal of clinical neonatology vol. 2,2: 61-9.

(3) Méndez-Sánchez N, Roldán-Valadez E and Flores MA (2001): Zinc salts precipitate unconjugated bilirubin in vitro and inhibit enterohepatic cycling of bilirubin in hamsters. Eur J ClinInvest.31;(9):773-80.

(4) Mendez-Sanchez N, Martinez M and Gonzalez V(2002): Zinc sulfate inhibits the enterohepatic cycling of unconjugated bilirubin in subjects with Gilbert's syndrome. Ann Hepatol. 1;(1):40-3.

(5) Rana N, Mishra S, Bhatnagar S, et al. (2011): Efficacy of zinc in reducing hyperbilirubinemia among at-risk neonates: a randomized, double-blind, placebo-controlled trial. Indian $\mathbf{J}$ Pediatr.78 (9): 1073-8.

(6) Blindauer CA. (2013):Lessons on the critical interplay between zinc 
binding and protein structure and dynamics. J InorgBiochem; (121):145-155.

(7) Hansen TWR, Nietsch $L$ and Norman.

E (2015):Reversibility of acute intermediate phase bilirubin encephalopathy. ActaPaediatrica, International Journal of Paediatrics98(10): 1689-1694.

(8) Ahmadpour-kacho M, Pasha YZ, Ranjbar B, et al. (2017): The Effect of Oral Zinc Sulfate on Serum Bilirubine Level in Term Neonates with Jaundice. Int $\mathbf{J}$ Pediatr.; 5(6): No.42.

(9) Boskabadi H, Maamouri G, Zadah HM, et al. (2015): Comparison of serum Zinc level between Neonates With jaundice and Healthy Neonates Shiraz E-Med J.; 16(11-12): 273-292.
(10) Saravanan Set al.(2017):Incidence of Zinc Toxicity as a Complication of Phototherapy; 5(4): 2023220236.

(11)

Mosayebi Z , Rahmani M , Ardakani S. B , Sheikh M , ShariatMandRezaeizadeh . G (2016) :Evaluation of serum zinc levels in hyperbilirubinemic neonates before and after phototherapy. Iranian journal of pediatrics; 26(3).

(12) El-Mazary A, Abdel Aziz $R$ and Sayed M (2017):Effect of Intensive Phototherapy and Exchange Transfusion on Copper, Zinc and Magnesium Serum Levels in Neonates with Indirect Hyperbilirubinemia. Mashhad University of Medical Sciences; 5(2): 4371-4383. 
Table 1 :Bilirubin levels in the studied patients:

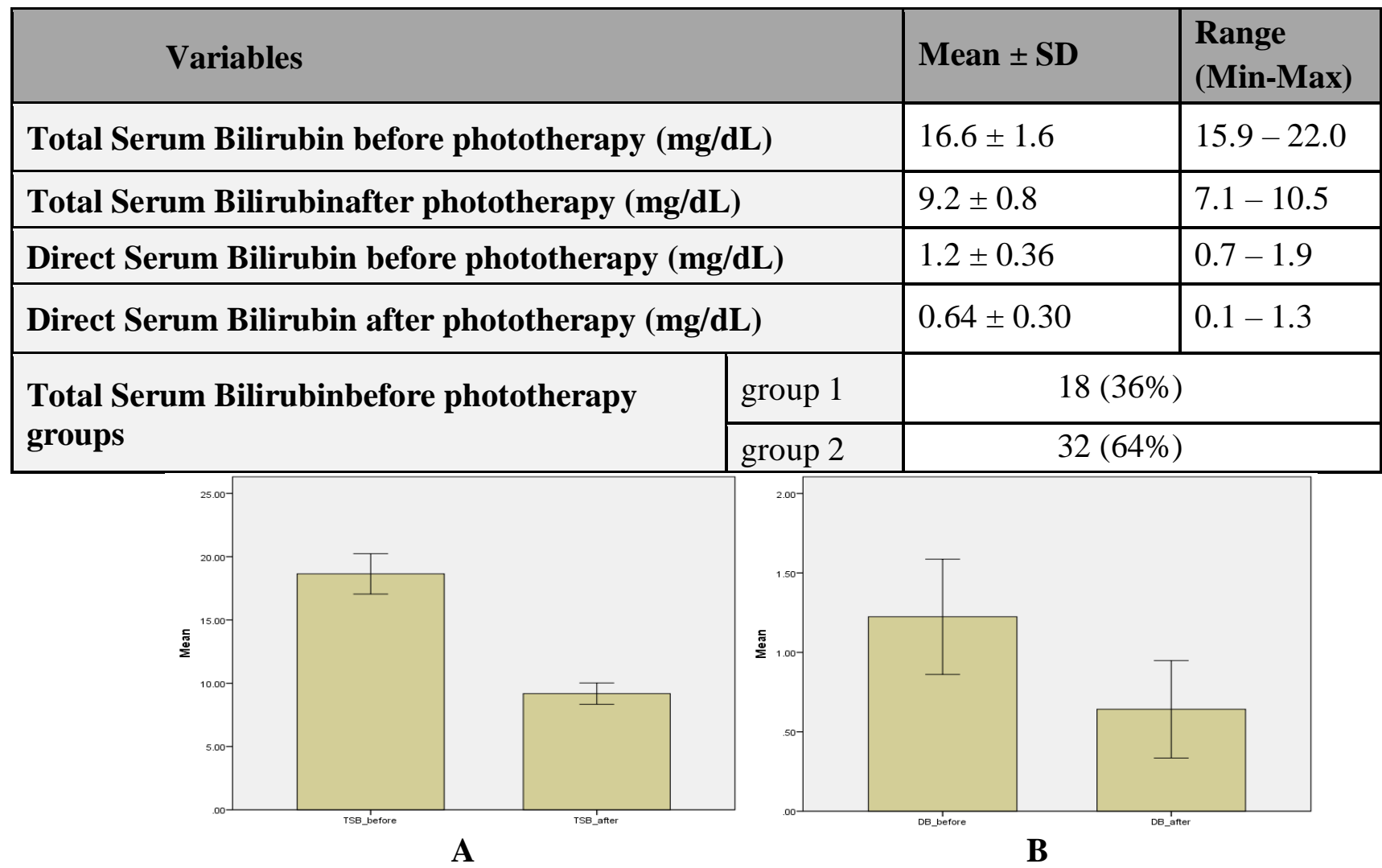

Figure 1:A.Total serum bilirubin level before and after phototherapy in the studied group, B. Direct serum bilirubin level before and after phototherapy in the studied group

Table 2:The type and duration of phototherapy between the studied groups

\begin{tabular}{|c|c|c|c|}
\hline \multirow{2}{*}{ Variables } & Group 1 & Group2 & \multirow{2}{*}{$P$ value } \\
\hline & No $(\%)$ & No $(\%)$ & \\
\hline \multicolumn{4}{|c|}{ Type of Phototherapy } \\
\hline 1. Conventional & $18(100 \%)$ & $2(6 \%)$ & \multirow{2}{*}{$<0.001$} \\
\hline j1Intensive phototherapy & 0 & $30(94 \%)$ & \\
\hline \multicolumn{4}{|c|}{ Duration of phototherapy (hours) } \\
\hline 1. Mean (SD) & $63.36 \pm 11.12$ & $54 \pm 11.06$ & \multirow{2}{*}{$<0.001$} \\
\hline 1. Median (IQR) & $72(48-72)$ & $48(48-60)$ & \\
\hline
\end{tabular}




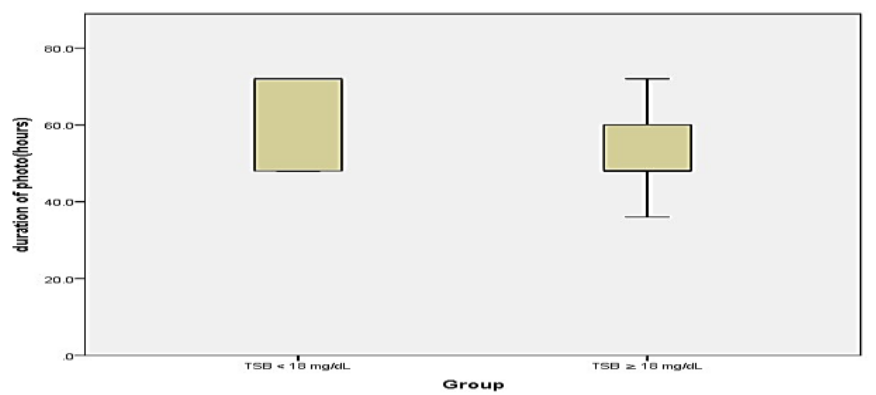

Figure 3: Duration of phototherapy in the study groups

Table 3 :The correlation between serum zinc level before and after phototherapy and serum bilirubin (total and direct) levels in the studied patients

\begin{tabular}{|c|c|c|c|c|}
\hline \multirow{2}{*}{ Variable } & \multicolumn{2}{|c|}{$\begin{array}{l}\text { Serum zinc level } \\
\text { before phototherapy }\end{array}$} & \multicolumn{2}{|c|}{$\begin{array}{l}\text { Serum zinc level } \\
\text { after phototherapy }\end{array}$} \\
\hline & $\begin{array}{l}\text { Correlation } \\
\text { Coefficient (r) } \\
\end{array}$ & $\underline{\text { P-Value * }}$ & $\begin{array}{l}\text { Correlation } \\
\text { Coefficient (r) } \\
\end{array}$ & $\underline{\text { P-Value * }}$ \\
\hline $\begin{array}{l}\text { Total serum } \\
\text { bilirubin before } \\
\text { phototherapy }\end{array}$ & $\underline{0.373}$ & $\underline{0.008}$ & $\underline{0.344}$ & $\underline{0.015}$ \\
\hline $\begin{array}{ll}\text { Total } & \text { serum } \\
\text { bilirubin } & \text { after } \\
\text { phototherapy } & \end{array}$ & $\underline{-0.126}$ & $\underline{0.383}$ & $\underline{0.038}$ & $\underline{0.796}$ \\
\hline $\begin{array}{ll}\text { Direct } & \text { serum } \\
\text { bilirubin } \quad \text { before } \\
\text { phototherapy }\end{array}$ & $\underline{0.191}$ & $\underline{0.184}$ & $\underline{0.148}$ & $\underline{0.305}$ \\
\hline $\begin{array}{lr}\text { Direct } & \text { serum } \\
\text { bilirubin } & \text { after } \\
\text { phototherapy } & \end{array}$ & $\underline{-0.136}$ & $\underline{0.346}$ & $\underline{-0.053}$ & $\underline{0.717}$ \\
\hline
\end{tabular}

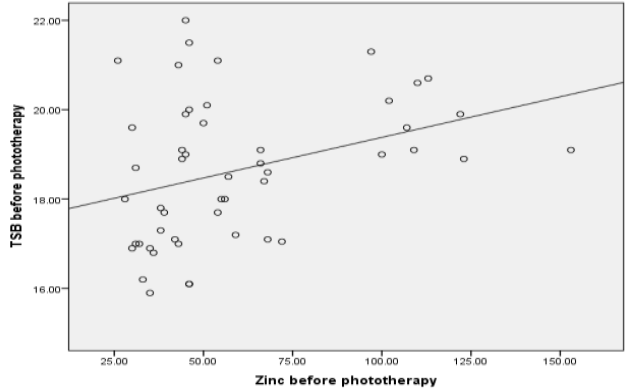

a

Figure 3: Correlation between serum $(\mathrm{mcg} / \mathrm{mL})$ zinc level and total serum bilirubin(TSB) level a: Before phototherapy, b:After phototherapy 